\title{
LOS CULTISMOS EN LAS NOTAS A PIE DE PÁGINA EN EL MANUAL DE GRAMÁTICA HISTÓRICA ESPAÑ OLA DE MENÉNDEZ PIDAL
}

\author{
José PERONA \\ Universidad de Murcia \\ Jose.Perona@um.es
}

\section{Petición de principios}

Si bien es necesario saber que la Gramática histórica de Menéndez Pidal es posterior a sus estudios sobre el Poema de Mio Çid, la lectura de las peticiones de principio de la Gramática deben ser leídas sin contextualizar, es decir, sin saber que, junto a la recuperación de la literatura, se estaba produciendo un elogio de la diferencia y, desde él, se construía una dialectología. Dialectología latina y dialectologías romances, forjadas juntas y a imagen y semejanza.

El problema de los cultismos, en el Manual de gramática histórica española, de Menéndez Pidal, está planteado de manera cruda. Construida la teoría de la evolución lingüística sobre las bases dialectales de la oralidad y, por ende, de la espontaneidad, las palabras patrimoniales del idioma son enfrentadas a las voces cultas, literarias, letradas, librescas: “... las palabras cultas no participan en toda la compleja serie de cambios que sufrieron en su evolución las voces primitivas del idioma".

Tienen, por eso, menos atractivo. No son complicadas a la hora de explicarlas. Como si la teoría se complaciese en la arqueología, en el enigma. Sus voces, además, tienen un defecto: no son populares. Por ello, "daremos aquí una idea de sus mudanzas, para no volvernos a ocupar de ellas".

Hay párrafos que son definitivos: "Las voces populares hoy usadas son la última fase evolutiva de las que componian el idioma latino vivo... merecen atención preferente por su complicado desarrollo, por ser en ellas donde se manifiestan en modo más completo las leyes fundamentales de la vida del lenguaje y por formar el fondo más rico del español y de su herencia patrimonial... las voces cultas, por la pobreza de su desarrollo, no ofrecen interés tan grande para la etimología y no hablaremos de ellas sino por nota...".

Si utilizáramos un adjetivo contemporáneo, podríamos decir que las voces patrimoniales, frente a las llamadas voces cultas, son pintorescas. Como pintoresco era el espíritu nacional que animaba a los investigadores a recorrer los profundos valles y los apartados riscos donde, en pleno proceso de industrialización, de la primera globalización, viviese el espíritu del casticismo.

José Álvarez Junco habla de la invención de la tradición, del invento del concepto de nación. La política lingüística de la nacionalización se puede observar en las ediciones de ciertas obras literarias y en la recuperación de Juan de Valdés (frente a Nebrija). Alejadas para siempre las obras escritas en árabe o en hebreo; estructurado un canon de autores latino-españoles (Prudencio, San Isidoro); desterrados centenares de textos latinos, la his- 
toria de la literatura española se aliaba con la dialectología para fundamentar la historia de la lengua. De los textos griegos, faltaría más, ni una palabra. Luis Gil ha escrito páginas excelentes sobre el particular. Podría decirse que en la historia de la lengua española, "Qui graecizabant, lutheranizabant".

Pasaremos por alto el debate casticista del siglo XVIII. Nos acercaremos a textos más próximos de Rafael Lapesa. Así, en 1963, se habla de fonología forzada a la hora de analizar los cultismos: "... fruto de la actividad lingǘstica consciente, de un criterio respetuoso o acomodaticio y de una voluntad que pretende superar las tendencias espontáneas de la evolución niveladora...". Y unos años después: "Desde el nacimiento de la lengua, las tendencias fonéticas fueron violentadas por el latinismo".

Las palabras de Lapesa contra el latinismo y el cultismo ponen como ejemplo señero la recuperación de los grupos consonánticos cultos frente a las preferencias de Juan de Valdés, considerado el vocero oficial del castellano. De esta manera, desaparecieron o fueron considerados vulgarismos conceto, vitoria, dino, coluna, leción ó lición abundantes en el lenguaje literario hasta el siglo XVII. Frente a ellos se impusieron concepto, victoria, digno, columna, lección... Pero Lapesa constata que hoy (1963) incluso los universitarios están aflojando esos grupos cultos, otrora tan denostados, y clama al cielo contra las pronunciaciones esamen, esigir, tasi, leción, produción. Lo que indica que a la hora de acercarse a los cultismos y a los latinismos habría que hacerlo desde la óptica histórica ${ }^{1}$.

De forma aparentemente paradójica con el modelo de la gramática comparada, son las palabras populares las que han de estudiarse como antiguamente se estudiaban los cultismos. No hay sino constatar en la edición de las obras clásicas los centenares, cuando no miles, de notas a pie de página que las acompañan. Vestidos, comidas, nombres de actividades agrícolas, nombres de frutos, flores, árboles, etc... se han convertido en arcaísmos. Es decir, en palabras pertenecientes a una lengua muerta, cuyas palabras hay que estudiar como si fuesen restos arqueológicos.

La pérdida de la importancia de la agricultura y de la ganadería y la transformación de la sociedad española, que en un siglo ha pasado del $70 \%$ de población dedicada al sector primario a dedicarse a los servicios en la misma proporción, ha convertido a las palabras patrimoniales en librescas. Por poner unos ejemplos: en los últimos años de la carrera de Filología Hispánica, he subrayado las palabras que eran desconocidas por la mayoría o la totalidad de mis alumnos. Aparte de las mencionadas, he aquí una breve lista: cecina, otero, cabildo, cedazo, humear, clueca o llueca, jamelgo, cisma, puches, cocedra, ero, pañizuelo, alborço, punchar, petral, behetría, desuno, chicharo... De los topónimos y antropónimos, prefiero callar.

\section{Las leyes fonéticas del castellano y sus excepciones cultas}

El inventario de leyes fonéticas que se presenta a continuación esta tomado de la Gramática histórica de Menéndez Pidal. Debajo de cada ley, se agrupan las palabras que, a pie de

1 Cualquier profesor que se dedique a explicar historia de la lengua española o gramática histórica de la misma se encuentra en una situación cuando menos curiosa. No es que los alumnos ignoren las etimologías latinas o la conjugación o los sufijos, sino que ignoran el significado de las palabras castellanas. Parece predecible que algunas de las palabras estrellas del Manual sean desconocidas: así, pestorejo, somormujo, alnado, columbrar, medrar, reñilla, ábrego, enebro, herrén, calaña, lua, etc... Ni qué decir tiene cuando en un texto aparece un topónimo que no pertenezca a sus cuarenta kilómetros cuadrados o que no salga mucho en la televisión. 
página, Menéndez Pidal considera cultismos o semicultismos, es decir, palabras que incumplen la ley fonética de que se trata. Las informaciones sobre el autor, el año, el siglo o la obra que van entre paréntesis están tomados del Diccionario crítico etimológico castellano e hispánico, de Joan Corominas y José Antonio Pascual, así como las apostillas (apreciaciones morales, pronunciación de clases cultas, estilo elevado y arcaizante, arcaísmos, vulgarismos, lenguaje afrancesado, etc...) y explicaciones divergentes que, respecto de la etimología o explicación pidalina, constan en el mentado diccionario.

Frente a estudios como los de Bustos Tovar, Gloria Clavería o Herrero, y otros que se podrían aportar sobre los latinismos de Berceo, Juan de Mena, Góngora, etc..., o sobre la incorporación masiva de palabras grecolatinas tomadas del francés en los siglos XVIII y $\mathrm{XIX}$, los ejemplos aducidos en la gramática pidalina abarcan 10 siglos, desde los orígenes del idioma hasta el siglo XX o al menos, hasta los años de la primera redacción del diccionario de Corominas. No trata esta nota de la complejidad de la distinción entre cultismos, latinismos, tecnicismos... de estudios posteriores a la Gramática... ni de estudios particulares sobre la obra de tal autor o siglo. Se trata, tan sólo, de inventariar todas las palabras consideradas cultismos en la citada obra de Menéndez Pidal.

Así pues, y a pesar de las palabras del Manual... sobre la vigencia temporal de las llamadas leyes fonéticas, se infiere que los cambios fonéticos que se reseñan son eternos $o$, al menos, atemporales. Es decir, que siempre, siempre, deben cumplirse y que todas las palabras que las incumplan son consideradas cultismos, independientemente del año o el siglo en que se incorporan al castellano.

\section{Las leyes fonéticas y los cultismos según Menéndez Pidal}

1. $\mathrm{AU}>\mathrm{O}$

Cultismos. Claustro (1209, Berceo). Cáustico (1535, Fernández de Oviedo). Fauce (1624, Huerta; Calderón). Salto (Cid, Berceo; saltar, Berceo. Calza. Falso (Glosas, Cid. Pronunciación de clases cultas, apreciaciones morales).

2. E breve tónica $>\mathrm{IE}$

Cultismos. Preces (Berceo; prieces: Berceo, Alexandre; prizes, J. Ruiz. Semicultismo. Estilo elevado y arcaizante). Centro (Alfonso X: Libros del saber de astronomía). Templo (Berceo. Popular: tiemplo. Muy usado en la escritura y no ajeno al uso oral). Séptimo (Berceo). Gente (Antiguo: yente: Cid, Berceo. La grafia G puede representar una Y. En el siglo XIV se generaliza gente. Hoy día, en plural, gentes, propia de escritores afrancesados).

3. I breve $>\mathrm{E}$

Cultismos. Libro (Orígenes del idioma). Digno (Berceo; dinno: Cid. Edad Media: dino. Nebrija, A. Palencia: digno) Continuo (h. 1400: Glosarios de Toledo. Frecuente en los siglos XV-XVII fue la forma vulgar contino: Álvaro de Luna, Santa Teresa).

4. O breve tónica $>$ UE.

Cultismos. Fosa (1542, Diego Gracián; Antiguo y popular, fuessa: 1200. Libro de Alexandre: fossa. Siglo XV. Huesa. "Sepultura, tumba", contraria a la regla F > H). Cómputo (Paravicino, + 1613). Órgano (Berceo, instrumento musical; Popular, uérgano: 1294; 
Primera Crónica General, huérgano; En el Siglo de Oro y hasta el siglo XVIII, existió el vulgar buérgano > muérgano.) Nota (Alexandre, "número, guarismo"). Molde (semicultismo, H. 1400, Glosario de Toledo. Probablemente, del catalán antiguo motle. Menos verosímil es que sea semicultismo, pues debería haber dado *modulo o mueldo). Rolde (del catalán antiguo rotle, por vía semiculta, del latín tardío Rotulus).

5. U breve $>\mathrm{O}$

Cultismos. Púrpura (Cid: pópola; Púrpura: Berceo, Alexandre. La conservación de la vocal postónica es normal en esta posición, según la fonética castellana: tórtola, miércoles, víspera, áspero). Número (1433: Villena; Nebrija. La solución nombre es catalanismo o galicismo). Mundo (Semicultismo: Cid. Debió existir esporádicamente la forma popular mondo. Rima: restitución de la pareja mundo / redondo. El cultista mundo: sermones eclesiásticos). Cruz (Semicultismo: 960; Cid. Conservado en todas las lenguas, salvo portugués y castellano en su forma popular). Bula (Nebrija: Tuvo ancha extensión la variante semiculta bulda (siglo XVI). Lucro (Logro: s. XIII, manuscrito bíblico: traduce usura; Autoridades: Lucro. Lucrar, DRAE, s.XIX). Sutil (< Subtilis). En la Edad Media, sotil. No hay, por lo tanto, razones perentorias que obliguen a suponer que sutil sea cultismo en castellano, pues el paso de $\mathrm{O}>\mathrm{U}$ es normal (ante I, claro). Desde el Siglo de Oro tiende sutil a restringirse a las acepciones morales y a caer en desuso en el lenguaje del vulgo ciudadano, pero esto es secundario. Podemos mirarlo como voz enteramente hereditaria o, a lo más, semicultismo. Como resultado del uso hoy predominantemente culto, ha habido quien pronunciara bárbaramente sútil (influyendo también inconsútil).

6. $\mathrm{O}+\mathrm{NY}>\mathrm{U}$.

Cultismos. Demonio (Berceo; Ajeno a muchos textos medievales, donde aparece diablo, más popular. Eufemísticos: demontre, demonche. Popular: demuño). Patrimonio (Padrimonio: 1212; patremonyo: 1300). Testimonio (Glosas de Silos).

7. $\mathrm{AI}>\mathrm{E}$

Cultismos. Jactarse (Glosas Silenses: iectare; Fuero de Medinaceli: echar; Marqués de Santillana, Antonio de Guevara: jactarse). Maxilar (Berceo: maxiella; Maxilar, sine data). Taxativo (Diccionario de Autoridades; taxare: A. de Palencia: tassar; Cancionero de Estúñiga: tasa; Nebrija: taxación). Tratar (Berceo, Alexandre)

\section{I breve $>\mathrm{E}$}

Cultismos. Vigilia (Cid: velar, vigilia). Dictado (Berceo: dictar; vacilación medieval: dic$\operatorname{tar}$ / ditar; Berceo: dictado). Minuto (A. de Palencia; la forma vulgar extendida es menuto). Tributo (Berceo, A. de Palencia, Nebrija; popular, trehudo, hoy treudo). Vigor (Cid). Viciar (J, de Mena; antiguo y vulgar, enviciar). Historia (Berceo: estoria / historia. La segunda se generaliza a finales de la Edad Media). Inclinar (Cid: enclinar; Berceo: inclinar).

9. $\mathrm{U}$ breve $>\mathrm{O}$

Cultismos. Lucrar (Academia, s. XIX; siempre, lograr). Duplicar (A. de Palencia: doblegar; tal vez catalanismo por su tardía aparición; duplicar, 1584) 
10. $\mathrm{AU}>\mathrm{O}$ (Videtur 1$)$

Cultismos. Audaz (Santillana; Audacia: Cancionero de Baena). Aumento (Santillana: augmento; Juan de Ávila: aumento). Aurifero (Sine data). Tauromaquia (Academia, s, XIX). Caución (1590; cauto: s. XV).

11. Pérdida de la vocal postónica

Cultismos. Colorar (Juan Ruiz, A. de Palencia). Luminaria (Berceo: lumbrera; ant. lumbraria; luminaria: s.XV. Rara iluminaria). Colocar (S.XIV). Literato (Berceo: letrado; Juan de Mena: literato. También, literatísimo). Pectoral (sine data). Secular (Berceo: seglar; A. de Palacio: secular). Roborar (Diccionario de Autoridades). Laborar (Cid: labrar; Laborar: duplicado semiculto: sine data). Temperar (Berceo: temprar; J. Ruiz: templar). Limitar (Corbacho).

12. Pérdida de la vocal protónica

Cultismos. Vindicar (Cid: vengar; más arcaizante, vendegar; Villena: Vindicar: no consta en Nebrija ni en Covarrubias). Adjudicar (Ercilla: 1570). Menester (Cid: de Ministeriu: la apócope de la -o final se explica por el uso proclítico de la palabra; la forma común es mester, con una síncopa fonética, aunque no es normal tal fenómeno ante el grupo -STDebió darse una confusión latina entre ministerium y mysterium: la función religiosa, desempeñada por un minister, rozaría con ministerium. ("Es menester", pasaría de significar "es servicio", "es útil" a (ergo) "es preciso".)

13. Mantenimiento de doble protónica

Cultismos. Episcopal (sine data), frente a bispal (Berceo), obispal (Nebrija). Fidelidad, 1490. (1206, fieldad; hasta Covarrubias). Comunidad (sine data); Recuperar (Oudin, Autoridades).

14. Mantenimiento de postónica. Palabras esdrújulas

Cultismos. Físico (Físico:berceo); Médico (A. Palencia. Adjetivo: Laguna). Trípode (trepedes, trevedes, estreves...); Vispera (Berceo: La conservación de la -E- postónica es normal, aun en voces populares, en esta combinación consonántica: áspero, árboles, miércoles, níspero... Existe, no obstante, la variante viespras). Áncora (s. XIII. Ancla, ultracorrección de ancra, leonesismo). Anima, ss. XI-XII (Álima, vulgarismo antiguo); Décimo, Berceo, poco extendido en la Edad Media; Famélico, 1528, A. de Guevara (duplicado semipopular, jamelgo); Pólipo (J. Ruiz, polpe. En latín, polipos, aunque tenía $\mathrm{O}$ breve, debió de pronunciarse con timbre cerrado de esta vocal, como suele suceder en los helenismos: torno, golfo, golpe); Ínsula: latín vulgar *islla y también *isula, distinguidas local o socialmente. Insulina, por extractarse de las isletas Langerhaus en el páncreas; Rápido: La Celestina; Rabdo > raudo (Los adjetivos en -IDUS no se sincopan nunca en castellano, sino que pasan a - ÍO: 1ucio, lacio, limpio, tibio... Quizá Rápido por semicultismo, ya que raudo es poético. Así pues, hay que postular otra etimología: *RAPITUS (por la-I-, por la $-\mathrm{D}-$ ).

\section{I final $>\mathrm{E}$}

Cultismos. Metrópoli (1580, A. de Morales, sin -S; videtur: ristra de "cultismos" derivados de metro); Diócesis (A. Palencia, sin -S: predominó la acentuación griega); Crisis (Autoridades: lengua de la medicina; las acepciones figuradas y no médicas se 
importaron del extranjero (sic)); Análisis (Lope de Vega: cree que es neologismo y lo reprueba; prefiere resolución); Síntesis (1708, Autoridades; del álgebra y de la filosofía); Génesis (1608); Raquis (Academia, 1884: de la biología y de la lengua de los naturalistas); Pelvis (Academia, 1884); Bronquitis (no lo he encontrado); Áspid (aspe, 1494; áspid, A. Palencia).

16. E final $>$ CERO; a veces, $-\mathrm{O}>\mathrm{CERO}$

Cultismos. Sede (1266; Seo, aragonesismo o catalanismo; Sede: 1595: No consta en A. Palencia, Nebrija, Percivale, Oudin); Sacerdote (1209); Ónice (1609); Clemátide (1555); Lene (Modernamente de volvió a tomar del latín con carácter culto); Paraselene (¿?); Rene (ren, femenino, en el Fuero Juzgo); Felice, infelice (Italianismo); Fenice (Cristóbal de las Casas: Fénix; Lope de Vega, fenis); Coce (Berceo); Miese (Berceo, con y sin -E: el idioma vaciló largamente. Nebrija: miesse.

17. $-\mathrm{U}>\mathrm{O}$

Cultismos. Tribu (A. Palencia); Continuo; Ímpetu ( $1^{\text {a }}$ mitad del siglo XV; Nebrija); Ángelus (Berceo, Primera Crónica General); Nicodemus; Virus (Academia, 1817: tecnicismo hoy bastante difundido); Venus. Golpe $(<*$ Colopus $<$ lat. Colaphos, del griego). La no diptongación de $\mathrm{O}$ breve tónica no es rara en un helenismo, pues, aun siendo vocal breve la ómicron griega, también era cerrada (torno, goldre). La -e final ( por -o) es de naturaleza estrictamente fonética y castizamente hispánica, pues hay un numeroso grupo de palabras donde existe ese cambio cuando una $\mathrm{U}$ latina sigue a una $\mathrm{O}$ tónica. Ej.: doble, cobre, molde, rolde, don e), goldre y el sufijo OTE. Y quizá boje). Sacramento. Pop., sagramento; ant., sagramente.

18. J, G inicial + vocal palatal tónica $>Y$

Cultismos. Género (1400, A. Palencia); Gente (Cid: yiente: la grafía Gente puede representar a "yiente"; ya es latinizante Gente, en Berceo. Su uso es general en plural: las yentes. A fines de la Edad Media empieza a ser común el singular, quedando el plural para uso eclesiástico; Hoy, el uso del plural es propio de afrancesados (Baralt).

19. Las consonantes intervocálicas se pierden

Vulgarismos. Tuavia (Berceo; popular: tovía, entoavía, entodavía, entuavía, entoadia; entadía, en charro salmantino.); Trabajaor. (Trabajador, hacia 1579); Peazo (Pedazo, 1070) no es un vulgarismo. Nido. La conservación de la -D- postónica es regular en castellano (tibio, etc...). Su pérdida - nio - es propia de la pérdida moderna de toda -D- castellana intervocálica.

20. J, G inicial + vocal palatal átona > CERO

Cultismos. Gentil (Glosarios de Silos); Gigante (Berceo); Giba (A. Palencia: La introducción de estos latinismos se debe al deseo de evitar expresiones humillantes para el afectado, si bien "giba" se ha hecho tan cruel como sus sinónimos populares: corcova, joroba...); Jacinto (1432); Gemir (hacia 1400; hasta el Rimado de Palacio, gemer; antiguamente, "emer"). 
21. J, G iniciales + vocal posterior $>\mathrm{Y}$

Cultismos. Junco, junta y topónimos.

22. SC- iniciales $>$ Esc-

Cultismo. Cetro (Berceo, ceptro; Nebrija, cetro); Ciencia (Berceo; antiguo, esçiençia: Vida de San Ildefonso); Cisma (1398, Rimado de Palacio); Escena ( Scaena, 1577; Cena: comida de la tarde, por latinismo, en Nebrija; escénico ya es castellano en A. Palencia, quien empleó "scena" en contexto castellano, pero es dudo que la considere castellana y no meramente latina); Pasmo (A. Palencia: latín clásico, spasmus; latín vulgar, pasmus; Nebrija pasmo, por espasmo (spasmus cynicus); espasmo, Laguna. El diccionario de Autoridades lo considera anticuado. [Ya en latín, dice Corominas, se agregaba una I breve ante la S- líquida, confundiéndose así con el prefijo EX -).

23. GL- iniciales $>$ L

Cultismos. Gloria (Berceo: uso eclesiástico; Cultismo antiguo y arraigado); Globo (1440, A. Torre, Santillana; el primero lo castellaniza, al definir la palabra latina; a fines del siglo XVIII, el globo, antes ocular, ahora terráqueo, es afrancesado. Falta en todos los diccionarios y vocabulario: Nebrija, C. De las Casas, Percival, Covarrubias.)

24. $U A>U$

Cultismos. Cualidad (sine data); Cuadrúpedo (Diccionario de Autoridades; antes, cuadrúpede; en Juan de Mena, cuadrupedal); Cuaderno (Berceo; aragonés antiguo, quadernio); Cuestión (Berceo, con el significado de pregunta); Cuodlibeto (sine data; cudlibético, cuodlibetal).

25. Las consonantes sordas intervocálicas sonorizan

Cultismos. Capitulo (D. Juan Manuel; Berceo: capítolo); Epistola (A. Palencia; según el diccionario de Autoridades, se encuentra ya en Las Partidas); Ocupar (Juan de Mena); Insípido (1530, Antonio de Guevara); Cátedra (Berceo; Juan Ruiz: cadera); Voto (Votum: Berceo; duplicado popular, boda; Glosas de Silos: vota, con grafía latinizante); Votivo (Según el diccionario de Autoridades, entró en el siglo XVII); Rotundo (1684; redondo, 1020); Minuto (A. Palencia; Berceo, menudo; popular, menuto); Metal (1250: Setenario; catalanismo; Fuero Juzgo, metallo; falta en muchos escritores de la Edad Media); Plátano (Juan de Mena, acentuado en la penúltima sílaba; proparoxítono, Laguna); Pacato (Diccionario de Autoridades; 1499: pacado; pazguato, "simple"); Cicuta (1499; Ceguta: Nebrija, Laguna, Covarrubias; también, dice Corominas, ceguda); Fecundo (Santillana, Góngora, Paravicino; falta en Nebrija y en Covarrubias; C. De las Casas traduce el italiano "fecundo" por abundante); Sofocar (1587: la variante más cultista, sufocar, es la preferida en el diccionario de Autoridades); Delicado (La Celestina; delgado, Berceo); Sabuco (Fines del siglo XIII, Nebrija; sauco, 1242). Pero: SETA, según la Academia, procede de SAETA...y según Corominas, es "inverosímil el tratamiento culto en vocablo de tan baja estofa y en noción de índole tan popular"...Por ello, propone SAEPTA como etimología.

26. La $\mathrm{F}$ intervocálica $>\mathrm{V}$

Cultismos. Defender (semicultismo, muy antiguo; Defensa: A. Palencia; Juan Ruiz, defesa; duplicado popular, dehesa; Más antiguo, defendimiento o el culto y clásico, de- 
fensión); Profesar (Aldana; profesión, "oficio", Berceo); Profundo (Juan Ruiz; hondo, Berceo); Edificio (1275); Elefante (1251; elifant, Libro de Alexandre); Refundir (M. de Ágreda, + 1665); Referir (hacia 1440); Rugido (Rugir, 1570; Roído, Cid; Ruido, Juan Ruiz, D. Juan Manuel); Sagitario (sine data; saetero, principios del siglo XVII; diccionario de Autoridades); Vigilar (Vigilia, Cid; Vigilar, diccionario de Autoridades); Magisterio (A. Palencia); Mágico (El Corbacho); Majestad (sine data); Leyenda (Berceo).

\section{L.L, NN $>11$, ñ. (LD, ND)}

Cultismos. Ilustrar (Juan de Mena; ilustre, hacia 1440); Colegio (Marqués de Villena, A. Palencia); Colega (1545; A. Palencia, latinismo sin equivalencia); Bula (Nebrija; bulda, semicultismo); Anales (hacia 1457); Péndola (Péñola, Libro de Alexandre; con tratamiento semiculto, se conservó primero la NN geminada y después se diferenció en ND, de donde péndola, variante usada no hace mucho en América; para el lit. granadino de 1601, en Andalucía es pendula, siendo peñula castellano de Castilla); Celda (Cacionero de Baena; cella, Primera Crónica heneral; el grupo LD es un esfuerzo fracasado por pronunciar la doble LL latina: Berceo, ciella, luego, cilla).

28. -RS- > s

Cultismos. Persona (cultismo popularizado desde fines de la Edad Media; pronunciación vulgar, persona, que debe ser muy antigua); Verso (Juan Ruiz; como adjetico, Academia, 1925; antiguo y popular, viesso); Curso (1594); Reverso (hacia 1575; popular castiza, revés); Converso (Nebrija).

29. -MB- $>M$

Cultismos. Envidia (Berceo); Tumba (Berceo); populares: comenencia, tamien.

30. $-\mathrm{MN}-, \mathrm{NN}>\tilde{\mathrm{N}}$

Cultismos. Columna (Berceo, columpna; semipopular, coluna, Nebrija); Solemne (sine data: 1399: solepme, también solepne, soleme. Antiguamente, lo usual era solene. Covarrubias lo latiniza: solemne); Omnipotente (Berceo; Omnipotencia, 1499).

31. -NG- > NZ (̃̃)

Cultismos. Ángel (Cid: La pérdida de la vocal final -o no es regular en la fonética castellana). Longitud (1492).

32. Las vocales postónicas se pierden. Las consonantes sordas sonorizan.

Cultismos. Duplicar (A, Palencia); Petrificar (sine data); Demacrado (sine data); Eclesiástico (1280); Sacramento (sine data: Cuento de Otas, sagramento; antiguamente, sagramente).

33. -PT-, -TT- $>$ T

Cultismos. Lapso (1554. Falta en el Siglo de Oro. Después se ha afirmado en el idioma culto. Relapso, 1595). Aceptar (Nebrija: antiguamente, acetar, incluso en Covarrubias. El vulgarismo aceutar está muy extendido); Exceptar (sine data); Concepto (1460. "dicho ingenioso", del italiano); Precepto ( $1^{\text {a }}$ mitad del siglo XIV). 
34. $-\mathrm{CT}->\mathrm{CH}$

Cultismos. Defecto (Gómez Manrique: Defeto, mediados del siglo XV); Docto (Jiménez Paton: Santillana, Juan de Valdés: doto, dotto); Nocturno (Juan de Mena); Pacto (Nebrija); Acto (Berceo); Tacto (Nebrija).

35. $-\mathrm{X}->\mathrm{CS}>[\mathrm{X}]$

Cultismos. Examen (El Corbacho: Nebrija, esamen); Exento (El Corbacho: Nebrija, esento); Eximir (Marqués de Santillana); Exorcismo (Berceo); Exhortar (Marqués de Santillana).

36. $-\mathrm{GN}->\tilde{\mathrm{N}}$

Cultismos. Pugnar (Siempre en El Quijote: Berceo, puñar, punar; puño, 1064; pugna, Glosas; pugna, diccionario de Autoridades). Signar (sine data: sinarse, "santiguarse", Berceo; señar, pronto anticuado); Maligno (sine data: Berceo, Malingno; el popular malino tien gran extensión); Magnifico (Juan de Mena); Indigno (sine data: la pronunciación medieval, indino; en los siglos XVIII y XIX rima peregrino con dino, como hacía Cervantes en La Galatea, donde ya era una licencia poética); Insigne (1575, Ambrosio de Morales).

37. Consonante $+\mathrm{CL}, \mathrm{PL}, \mathrm{FL}>$ consonante $\mathrm{CH}$

Cultismos. Inclinar (Cid, semiculto por la I; Berceo: enclinar e inclinar; la lengua literaria tiende a generalizar la I); Inflamar (1475; El Corbacho, enflamar); Implicar (hacia 1440: plegar, semiculto: Libro de Alexandre, pregar; Purgatorio de San Patricio, plegar).

38. Los grupos de tres consonantes se simplifican

Cultismos. Instar (A. Palencia); Instrumento (A. Palencia; estrument, Berceo; estrumento, Juan Ruiz; estormento, Alfonso XI); Constitución (Berceo). Obscuro. Hasta El Quijote, escuro. (Berceo, J. Manuel: oscuro; Góngora, obscuro). La Academia le dio su preferencia a obscuro para acabar con escuro, que ya entonces se consideraba vulgar. Sin embargo, nunca se ha pronunciado así, y aunque la Academia ha mantenido pertinazmente esta grafía artificial, no ha sido sin protesta de la mayoría de escritores cultos (Unamuno, etc...). La grafía OBS- sólo en encuentra antes de Góngora en algún pedante a ultranza como APal., junto a escuro y oscuro.

39. La -Q- intervocálica sonoriza

Cultismos. Aquilón (Fernán González); Secuaz (fines del siglo XV; secaz, Santillana); Locuaz (Góngora); Escuela (Berceo; escola, 1192).

40. Los grupos de yod -DY-, -GY- >Y

Cultismos. Medio (Enrique de Villena: pronunciación distinguido; Medio $>*$ meyo $>$ meo, que es el presente del verbo mear); Repudio (A. Palencia: durante mucho tiempo, lenguaje forense; hoy sigue siendo puramente literario, aunque es muy usual); Odio (Berceo: poco empleado en la Edad Media; popular, aborrecimiento); Radio (principios del siglo XVIII; Berceo, rayo); Remedio (Berceo; Calila); Homicidio (principios del siglo XVII; duplicado popular en los siglos XI-XII, omezillo, aunque sospechoso de latinismo); Envidia (Berceo); Prodigio (A. Palencia; falta en Nebrija y en El Quijote, pero está en Covarrubias y 
en Góngora; muy generalizado actualmente en el habla de la gente educada); Sufragio (A. Palencia; quizá fue utilizado por Góngora, Lope y Paravicino como latinización ocasional); Refugio (Marqués de Santillana); Prestigio (diccionario de Autoridades: "concepto favorable, Gracián); Vestigio (hacia 1440, "planta del pie", "huella"; hoy, la lengua culta lo usa en sentido figurado).

41. -P'L- > -B'L- > LL

Cultismos. Copla (Cid, "serie de versos": semicultismo).

42. $-\mathrm{C}^{\prime} \mathrm{L}-$; $-\mathrm{G}^{\prime} \mathrm{L}->[\mathrm{X}]$

Cultismos. Siglo (Semicultismo, siglo XIV; Cid, sieglo, general en los siglos XIIXIII; secular, A. Palencia); Milagro (Nebrija; Cid, miraclo; Gran Conquista de Ultramar, miraglo; Berceo, miráculo); Peligro (semicultismo, Berceo; siglo XIII, periglo: "debe tenerse en cuenta que en el castellano primitivo el pueblo repuanaba a grupos del tipo GL, CL, desaparecidos del lenguaje vulgar gracias a la fonética histótica castellana, de suerte que habia tendencia espontánea a cambiarlos por GR, $\mathrm{CR}$, (perigro), más tarde peligro por disimilación, invertida justamente por la rsistencia popular contra el grupo GL"); Juglar (semicultismo, por la -U- sine data; jokulare, aragonés, 1072; joglar, Berceo); Báculo (1520; baclo, Castigos del Rey Don Sancho; baglo, Berceo); Regla (967; reja, Berceo); Secular (A. Palencia; seglar, Berceo); Legra (Libro de los caballos; légara; voz técnica).

43. $-\mathrm{T}^{\prime} \mathrm{L}->[\mathrm{X}]$

Semicultismos. Cabildo (1202; Berceo, capítulo); Tilde (1433, duplicado semipopular; título, Berceo); Rolde (antiguo; catalán y dialectal, rotle; Covarrubias, rótulo); Molde (1400; parece ser palabra tardía, no aparece hasta Percívale; castellano antiguo, motle; Juan de Mena, módulo); Eneldo (Libro de la Montería); Espalda (1488; duplicado culto, espátula); Hojaldre (A. Palencia).

44. Contra los cambios en las consonantes romances

Cultismos. Hábito (Nebrija; ábito, Berceo); Súbito; Rápido (La Celestina; raudo, Cancioneros, Herrera: pronunciación semiculta por su carácter poético; antiguamente, rabdo); Muslo (siglo XIII; músculo, diccionario de Autoridades); Mezclar (sine data); Ángulo (1256-1276; semipopular, anglo); Cingulo (sine data; cincho) Singularidad (sine data).

\section{Referencias bibliográficas}

Alvar, M. y Mariner, S. (1959): "Latinismos", en Elementos constitutivos del español. C.S.I.C., Madrid, vol. II, págs. 3-49.

Álvarez Junco, J. (2001): Mater dolorosa. La idea de España en el siglo XIX. Madrid, Taurus.

Azofra Sierra. Ma E. (2006): "Consideraciones sobre el concepto de cultismo", en Revista de Filología Románica, vol. 23. págs. 229-240.

Benítez Claros, R. (1959): "Clasificación de los cultismos", en Archivum, IX, págs. 216-227.

Bustos Tovar, J. J. (1974): Contribución al estudio del cultismo léxico medieval. Anejos del B.R.A.E. Cano, R. (2005): Historia de la lengua española. Barcelona, Ariel.

Clavería Nadal, G. (1989): El latinismo en español. Barcelona, Universidad Autónoma de Barcelona. 
Corominas, J., y Pascual, J. A. (1980-81): Diccionario crítico etimológico castellano e hispánico. Madrid, Gredos.

García de La Fuente, O. (1981): El latín bíblico y el español medieval hasta 1.300. Vol I. Gonzalo de Berceo. Instituto de Estudios Riojanos.

Gil Fernández, L. (1981): Panorama social del humanismo español (1500-1800). Madrid, Alambra.

Herrero Ingelmo, J. L. (2008): Cultismos renacentistas. (Cultismos léxicos y semánticos en la poesía del siglo XVI), en web.usal.es/ joluin/investigacion/cultismosrenacenintrodu.pdf

Lapesa, R. (1996): El español moderno y contemporáneo. Estudios lingüísticos. Barcelona, Crítica. Lloyd, Paul M. (1993): Del latín al español. I. Fonología y morfología históricas de la lengua española. Madrid, Gredos.

Menéndez Pidal, R. (1999): Manual de gramática histórica española. Madrid, Espasa-Calpe.

Penny, R. (1993): Gramática histórica del español. Barcelona, Ariel.

Perona, J. (2004): "El cultismo y el retorno del canon romántico", en Revista de Investigación Lingüistica, vol. VII, págs. 174-198.

Wright, R. (1989): Latín tardio y romance temprano. Madrid, Gredos. 